M. Tessler FRCPC, A. Dascal FRCPC, S. Gioseffini ART, M. Miller FRCPC, J. Mendelson FRCPC

\title{
Growth curves of Staphylococcus aureus, Candida albicans, and Moraxella osloensis in propofol and other media
}

Propofol, 2,6 diisopropylphenol, in an emulsion formulation (Diprivan), has been associated with postsurgical infections caused by Staphylococcus aureus, Moraxella osloensis and Candida albicans. These organisms were individually inoculated into each of the following media: (1) the emulsion preparation of propofol, (2) Intralipid 10\%, (3) pure 2,6 diisopropylphenol, and (4) trypticase soy broth (TSB). The organisms were incubated and subcultured hourly for eight hours at room temperature. Propofol supported the growth of all three organisms, but for $S$. aureus and $M$. osloenis, the growth rate was slower in propofol than in TSB $(P<0.05)$. There was no difference between the growth rate of any organism in propofol than in Intralipid $10 \%$. The authors conclude that propofol, in the emulsion formulation, supports bacterial growth and, therefore, must be prepared for administration in an aseptic manner. Also, by administering propofol soon after preparation, the risk of introduction of a significant inoculum to the patient will be reduced.

L'utilisation du propofol, ou 2-6 diisopropylphénol, sous forme d'émulsion (Diprivan) a récemment été associée à des infections postopératoires à Staphylococcus aureus, Moraxella osloensis et Candida albicans. Dans la présente étude, ces trois micro-organismes sont placés séparément dans chacun des milieux de cultures suivants : 1) propofol en émulsion, 2) Intralipide 10\%, 3) 2-6 diisoprophylphénol pur et 4) bouillon trypticase soja (BTS). Ces milieux colonisés sont incubés pendant huit heures à la température ambiante. Des cultures de chacun des milieux sont répétées à chaque heure. Les

\section{Key words}

ANAESTHETICS, INTRAVENOUS: propofol; BACTERIA: growth rates.

From the Departments of Anaesthesia and Medicine, The Sir Mortimer B. Davis-Jewish General Hospital and McGill University, Montreal, Quebec, Canada.

Address correspondence to: Dr. Michael Tessler, Department of Anaesthesia, Sir Mortimer B. Davis-Jewish General Hospital, 3755 Cote Ste. Catherine Road, Montreal, Quebec, Canada H3T 1E2.

Accepted for publication 8th January, 1992. résultats des cultures démontrent que le propofol permet la croissance de chacun des trois organismes. Cependant, la croissance du $S$. aureus et du $M$. osloensis est plus lente dans le propofol que dans le BTS $(P<0,05)$. La croissance des trois organismes dans le propofol est comparable à celle retrouvée dans l'Intralipide 10\%. Le 2-6 diisopropylphénol pur ne permet aucune croissance des organismes. Les auteurs concluent que le propofol sous forme d'émulsion est un milieu de culture potentiel pour différents micro-organismes et que toute manipulation de ce produit pour utilisation clinique doit se faire de façon aseptique. De plus, on recommande d'adminis trer le propofol peu de temps après l'aspiration dans une seringue afin de diminuer le risque d'infection chez les patients qui doivent recevoir ce médicament.

Propofol, 2,6 diisopropylphenol, a new intravenous anaesthetic virtually insoluble in water, is formulated in an aqueous soya bean oil emulsion similar to Intralipid $10 \% .^{1,2}$ Its advantages include smooth, rapid induction of general anaesthesia, a low incidence of nausea or vomiting, and quick recovery. ${ }^{3-6}$

Propofol emulsion (subsequently referred to as propofol) has been associated with postsurgical infections, either bacteraemia or wound infections. ${ }^{7}$ The organisms involved were Staphylococcus aureus, Moraxella osloensis and Candida albicans. The article reporting these infections suggested that contamination was extrinsic and stated that when incubated at $33^{\circ} \mathrm{C}$ in propofol, S. aureus rapidly proliferates. $^{7}$

It is not surprising that propofol supports bacterial growth. Intralipid $10 \%$ supports the growth of bacteria and yeast, and the Center for Disease Control (CDC) has recommended a 12-hr time limit for infusion of Intralipid $10 \%{ }^{8}$ The effect of adding 2,6 diisopropylphenol to $10 \%$ soya bean oil emulsion (Diprivan) on microbial growth is not known.

We therefore investigated and compared the growth rates of S. aureus, $M$. osloensis and $C$. albicans in the commercial emulsion formulation of propofol, Intralipid $10 \%$, pure 2,6 diisopropylphenol and trypticase soy broth (TSB). 


\section{Methods}

A few colonies of fresh overnight growth from each of Staphylococcus aureus, Moraxella osloensis, and Candida albicans were inoculated into separate test tubes containing TSB. The tubes were then incubated for 2-4 hours at $35^{\circ} \mathrm{C}$. This suspension was then diluted with TSB to obtain, visually, a turbidity equivalent to a $0.5 \mathrm{McFar}$ land standard (approximately $1 \times 10^{8}$ colony-forming units $\cdot \mathrm{ml}^{-1}\left(\mathrm{cfu} \cdot \mathrm{ml}^{-1}\right)$.

The suspensions were then diluted 1 in 100 in TSB $(\sim 1$ $\left.\times 10^{6} \mathrm{cfu} \cdot \mathrm{ml}^{-1}\right)$. They were further diluted 1 in 100 in each of the following: propofol for injection (Diprivan, ICI Pharma), 2,6 diisopropylphenol (Aldrich Chemical Co., Inc), Intralipid $10 \%$ (KabiVitrum Canada, Inc.) and TSB (Difco Laboratories).

One in ten serial dilutions in the respective test media of these $1 \times 10^{4} \mathrm{cfu} \cdot \mathrm{ml}^{-1}$ suspensions were prepared to obtain the final $1 \times 10^{3}, 1 \times 10^{2}$, and $1 \times 10^{1} \mathrm{cfu} \cdot \mathrm{ml}^{-1}$ suspensions to be tested.

The test tubes were incubated at room temperature $\left(22.5^{\circ} \mathrm{C}\right)$ and $0.1 \mathrm{ml}$ of the different suspensions were subcultured hourly for eight hours on to $5 \%$ sheep blood agar plates. At hours seven and eight, because of the increase in turbidity of the $S$. aureus in TSB, $0.001 \mathrm{ml}$ of the suspensions was also plated from the different media using calibrated loops.

These plates were then incubated for $24 \mathrm{hr}$ at $35^{\circ} \mathrm{C}$ and the number of colonies was counted on each plate.

\section{Data Analysis}

The individual organism growth patterns in each media were compared by analyzing the respective regression coefficients derived from a semi-log plot of the growth curves for the different inocula. The ability of the regression equation to account for the variance in the respective growth curve is given by the $\mathrm{r}$ value for each regression. Statistical comparisons between regression coefficients were done using standard methods. ${ }^{9} \mathrm{~A} P$ value of $<0.05$ was considered significant.

\section{Results}

The pure 2,6 diisopropylphenol was bactericidal. The other three media all supported growth of the three organisms. The growth curves for S. aureus are shown in Figure 1. The growth rate of $S$. aureus was significantly faster in TSB versus propofol at an inoculum of $1 \times 10^{3} \mathrm{cfu} \cdot \mathrm{ml}^{-1}$ by regression analysis. There were no differences at this inoculum between the growth rates of S. aureus in TSB and in Intralipid $10 \%$, or between Intralipid $10 \%$ and propofol.

There were also differences between the growth rates of $M$. osloensis in TSB and in propofol and TSB versus Intralipid $10 \%$ by regression analysis (at an inoculum of

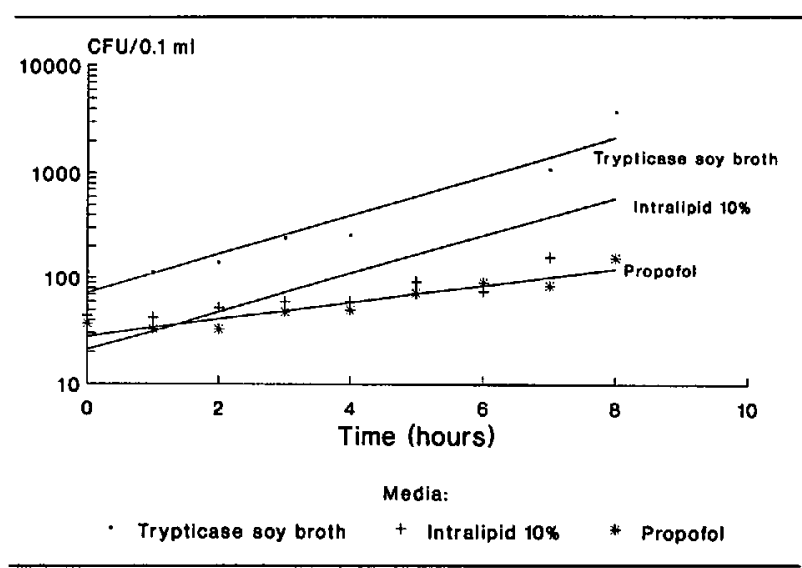

FIGURE 1 Growth of Staphylococcus aureus in different media. Inoculum of $1 \times 10^{3} \mathrm{cfu} \cdot \mathrm{ml}^{-1}$. Correlation coefficients (r): trypticase soy broth 0.96 , Intralipid $10 \% 0.73$, and propofol 0.94 . CFU: colonyforming units.

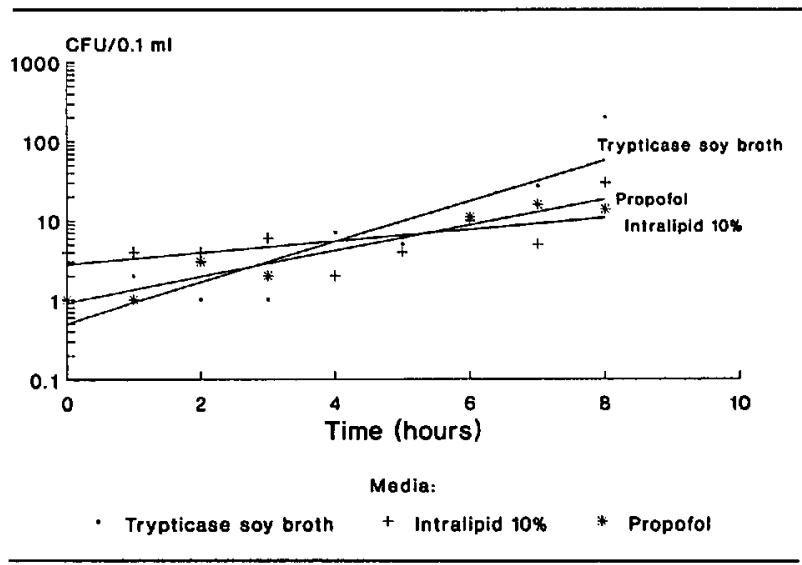

FIGURE 2 Growth of Moraxella osloensis in different media. Inoculum of $1 \times 10^{3} \mathrm{cfu} \cdot \mathrm{ml}^{-1}$. Correlation coefficients (r): trypticase soy broth 0.98 , Intralipid $10 \% 0.91$, propofol 0.98 . CFU: colonyforming units.

$\left.1 \times 10^{3} \mathrm{cfu} \cdot \mathrm{ml}^{-1}\right)$. There was no difference between the growth rates of $M$. osloensis in propofol versus Intralipid 10\% (Figure 2).

There were no differences among the growth rates of C. albicans at any dilution, in any of the media (Figure 3).

There were no significant differences between any of the growth curves in propofol, Intralipid $10 \%$, and TSB for any of the organisms using inocula of $1 \times 10^{2}$ or $1 \times 10^{1}$ $\mathrm{cfu} \cdot \mathrm{ml}^{-1}$.

\section{Discussion}

We have demonstrated that the emulsion formulation of propofol (2,6 diisopropylphenol in $10 \%$ soya bean oil, $1.2 \%$ egg phosphatide, and $2.25 \%$ glycerol ${ }^{1}$ ) will support the growth of $S$. aureus, M. osloensis, and C. albicans when this drug is inoculated with these organisms and 


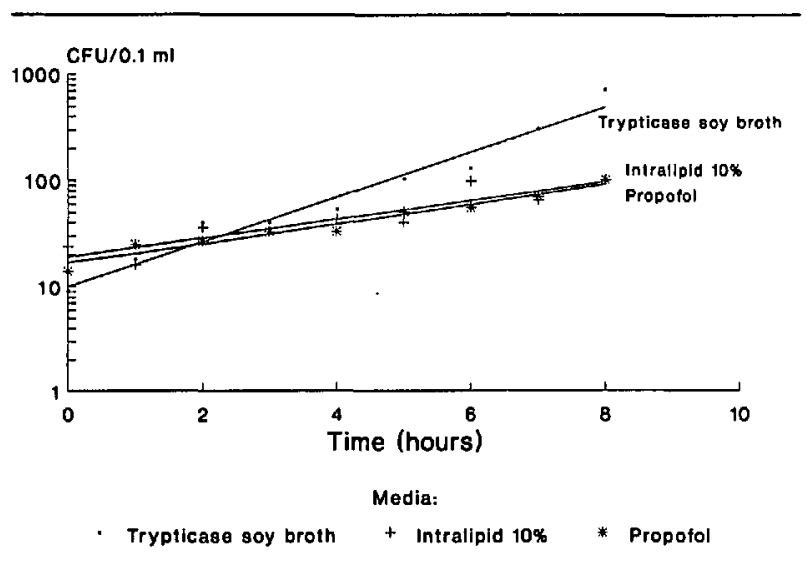

FIGURE 3 Growth of Candida albicans in different media. Inoculum of $1 \times 10^{3} \mathrm{cfu} \cdot \mathrm{ml}^{-1}$. Correlation coefficients (r): trypticase soy broth 0.9 , propofol 0.97 , Intralipid $10 \% 0.6$. CFU: colony-forming units.

incubated at room temperature. We therefore agree with other investigators who recommend that strict aseptic technique must be used when preparing syringes for infusion. ${ }^{10,11}$

The growth rates for S. aureus, M. osloensis, and C. albicans in propofol were the same as in Intralipid $10 \%$ over the eight-hour period of this study. Since the current recommendation is to infuse an intravenous lipid emulsion within $12 \mathrm{hr}^{8}$ it is appealing to suggest that propofol should have at least an eight hour time limit for infusion. We think it would be an error to make this suggestion because, unlike the situation with Intralipid 10\%, there are multiple opportunities for contamination of propofol from aspiration from the vial, until injection into the patient. ${ }^{12}$ If the propofol is contarninated, the longer it is allowed to remain in the syringe before use, the larger the inoculum that will be injected into the patient. It is therefore concluded that propofol be prepared for injection in a sterile manner and infused into patients soon after preparation, in order to reduce the possibility of injecting a significant inoculum.

Further, it appears that the size of the inoculum into the propofol affects the growth rate of the organism. With inocula of $1 \times 10^{3} \mathrm{cfu} \cdot \mathrm{ml}^{-1}$ of $\mathrm{S}$. aureus and $\mathrm{M}$. osloensis, the growth rates in TSB were faster than in propofol. However, there were no differences of the growth curves in propofol, TSB and Intralipid 10\% using lesser inocula of the same organisms. This lack of difference at low levels of bacterial contamination might reflect similar support for growth in propofol, TSB, and Intralipid $10 \%$. Similar support is unlikely, though, because previous authors' experience implies limited growth of bacteria in propofol when the inoculum is low. ${ }^{10,11}$

In summary, propofol supports the growth of S. aureus, M. osloensis, and C. albicans at room temperature.
Because of the multiple opportunities for contamination of propofol, it is recommended that it be infused shortly after aspiration into a syringe, to minimize any potential bacterial inoculum from being injected into the patient. Further, it is imperative that the propofol be prepared and administered in an aseptic manner to prevent injection of a contaminated solution.

\section{Acknowledgements}

The authors gratefully acknowledge the secretarial assistance of Mrs. Sarah Scholl and Miss Rosie Talaslian and Dr. Saul Wiesel for his suggestions in the preparation of the manuscript.

\section{References}

1 Doze VA, Westphal LM, White PF. Comparison of Propofol with Methohexital for outpatient anaesthesia. Anesth Analg 1986; 65: 1189-95.

2 De Sommer MRJ, Driessen JHJ, Willems CME, Lust PC. A comparative study on the effects of propofol in emulsion and Intralipid on fat metabolism. Acta Anaesthesiol Belg 1990; 41: 133-8.

3 O'Toole DP, Milligan KR, Howe JP, McCollum JSC, Dundee JW. A comparison of propofol and methohexitone as induction agents for day case isoflurane anaesthesia. Anaesthesia 1987; 42: 373-6.

4 Millar JM, Jewkes $C F$. Recovery and morbidity after day case anaesthesia. Anaesthesia 1988; 43: 738-43.

5 Sampson IH, Plosker H, Cohen M, Kaplan JA. Comparison of propofol and thiamylal for induction and maintenance of anaesthesia for outpatient surgery. $\mathrm{Br} \mathrm{J}$ Anaesth 1988; 61: 707-11.

6 Raeder JC, Misvaer G. Comparison of propofol induction with thiopentone or methohexitone in short outpatient general anaesthesia. Acta Anaesthesiol Scand 1988; 32 : 607-13.

7 CDC. Postsurgical infections associated with an extrinsically contaminated intravenous anesthetic agent - California, Illinois, Maine, and Michigan, 1990. MMWR 1990; 39: 426-33.

8 Crocker KS, Noga R, Filibeck DJ, Krey SH, Markovic M, Steffee WP. Microbial growth comparisons of five commercial parenteral lipid emulsions. J Parent Ent Nutr 1984; 8: 391-5.

9 Kleinbaum DG, Kupper $L L$, Muller KE (Eds.). Applied Regression Analysis and other Multivariable Methods. Boston: PWS-Kent Publishing Co. 1988; 91-2.

10 Downs GJ, Haley PR, Parent JB. Propofol: can a single ampule be used for multiple patients? Anesthesiology 1991; 74: 1156.

11 Goodale DB. Anesthesiology 1991; 74: 1156-7.

12 Kempen PM. Contamination of syringes. Can J Anaesth 1989; 36: 730-1. 